This PDF is a selection from an out-of-print volume from the National Bureau of Economic Research

Volume Title: Marriage, Family, Human Capital, and Fertility

Volume Author/Editor: Theodore W. Schultz, editor

Volume Publisher: Journal of Political Economy 82(2), Part II, April 1974

Volume URL: http://www.nber.org/books/schu74-2

Publication Date: 1974

Chapter Title: Comment: The Economics of Nonmonetary Variables

Chapter Author: William J. Goode

Chapter URL: http://www.nber.org/chapters/c3682

Chapter pages in book: (p. 27 - 33) 


\title{
Comment: The Economics of Nonmonetary Variables
}

\section{William J. Goode}

\author{
Columbia University
}

In the history of science researchers have often borrowed theories, analogies, or metaphors from other fields, usually the better-developed ones; in economic terms, they invested their human capital by acquiring new and presumably more-advanced intellectual tools. The most conspicuous borrowing in nineteenth-century social science was the unfortunately imaginary set of the developmental sequences of societies, worked out by anthropology and sociology on the basis of findings from biological evolution. It is less often that scientists in a relatively developed field become restive with its constraints and invade another with the aspiration that their more powerful technical and theoretical tools will solve problems with which the less-developed field has not adequately coped. (This is a challenge I have sometimes hurled at physicists who believe that the findings of sociology are simple-minded.) Over the past two decades, physicists tried this successfully in their contributions to molecular biology, and now economists have been expanding their world by attempting to analyze problems usually brooded over by sociologists, social psychologists, anthropologists, and political scientists.

In this case, interestingly enough, they will encounter colleagues in these fields who have themselves been moving toward economic or quasieconomic analysis of the same phenomena, though to be sure they have not attempted many social analyses of purely market processes. Especially in social psychology and sociology, a small group of theorists have for nearly two decades been working out exchange and allocational problems with the aid of economic ideas.

They have been hampered by their lack of mastery over the tools of economics, their failure to use economics explicitly, and their unwillingness-thus shouldering a burden economists of the past did not wish to carry-to do much theorizing without the facts. In my own case, I have 
been trying to understand social-control systems, of which monetary controls form one set, by considering how prestige, force and force threat, and love or affection are accumulated, allocated, or lost. Even in my monograph on divorce, written two decades ago, I was the first both to demonstrate rather fully the inverse relationship between class position and divorce rates (a prediction now made by Becker) and to give an essentially economic explanation for it (see Goode 1956, 1962).

The differing styles of economics and sociology prevent me from making an adequate, brief analysis of Becker's paper. I perceive many tautologies in the paper, but I know that disturbs an economist less than a sociologist. Where economists may be content with certain types of summary indexes, I want to see a large cross-table of percentages. Often I must respond by saying, in answer to an elegant set of mathematical formulas: "It is a beautiful flight but it is not reliable for transportation"; that is, it simply is not true-though that may seem to an economist only a crude answer. An example of this would be Becker's formulation that late marriage and the difficulty of divorce will be correlated. India, for example, has an early age of marriage but very difficult divorce; in the West the main line of division is between Catholic and non-Catholic countries, and in general Catholic countries have almost no divorce but a slightly earlier age at marriage (except for Ireland) than other Western countries; and so on. Of course, to an economist, that may seem at best an unimaginative answer.

In any event, though I am nervous about this invasion, I welcome it. In these few pages I shall look at only a few minor points in Becker's paper to illustrate a somewhat general problem that is often encountered in some explorations by economists.

A major source of weakness in this bold foray into intellectual fields such as sociology and political science that have been trying for generations to create an autonomous noneconomic body of theory is Becker's failure to be daring enough in a critical question, that is, whether any nonmonetary variables actually enter the calculations. In fact, as we see from the very first stages (Becker 1973, p. 817), both the market and nonmarket variables are aggregated to explain $S$, which is the "full income, the maximum money attainable if the $w_{j}$ [i.e., wage rates, of the $j$ th member] are constants."

Although I believe this monetary emphasis may ultimately be a weakness, since the noncontractual structure of exchanges in those sectors may create different behaviors than in the monetary sector, ${ }^{1}$ we are left with no assurance that the broadened economic formulation will be adequate, since in fact it has not been fully built into the equations or tested. That

1 This matter is analyzed at length in my The Celebration of Heroes: Prestige as a Control System (forthcoming). Meanwhile, see my Explorations in Social Theory (1973). 
is, the nonmonetary variables have not been given due weight, but have been monetized.

That monetary equivalent, so tempting to the economist because of his past training, can create both obstacles and factual errors in the analysis. Perhaps I should add a theoretical point, that since the income figure is purely hypothetical or imaginary, it has no greater degree of reality than an apparently subjective factor such as prestige.

To take a minor example, education is worth something on both the market and nonmarket exchange systems, and for some purposes a high education can be given an equivalent monetary value, but for a man with little education, a wife with very much education is not worth as much as one would suppose from her money value on the larger market. She is a less-fit wife for him, by nonmonetary calculations-which would still be economic-and he would be supported in this low evaluation by his social circle.

Let us consider at length a more elaborate instance of the problems this failure creates, specifically the lines of reasoning as to whether and why polygyny occurred and why it has usually been the upper-strata men who could or did take advantage of this opportunity. The case is instructive, for the focus on total monetary income leads to factual errors and obscurities, but a general focus on nonmarket economic analysis would clarify some of the facts we do know and leave one question unsolved but at least not obscure.

Becker reasons-correctly, I think-that the total monetary output of monogamy would be higher than that of either polyandry or polygyny. Here the facts are more powerful than he supposes, for whether or not multiple marriage was permitted or encouraged, it has not been common in any society, except under very special conditions. For most men, in all societies over time, polygyny was a statistically unlikely delight.

Obviously, a very low ratio of men to women-caused by successful conquests or by high death rates in war-might permit polygyny for a while, but such conditions are not likely to continue for long. Late marriage for men and early marriage for women raise the chances somewhat, but high mortality among women keeps the total number of woman-years available to each man rather limited. As a consequence, polygyny has not been general even where it is approved.

A purely market explanation may yield this aggregate result even if, as I believe, the reasoning in its favor (see his section 3, above) is tautological. That is, for most men and women the net market payoff is higher if they pair together rather than make other types of arrangements. However, this reasoning fails at the next step, the explanation for the unequal distribution of women among men even where polygyny is permitted.

At this next step it is necessary to give due weight to strictly nonmonetary factors. First, Becker argues (see his section 3, above) that the 
"total output over all marriages could be greater if a second wife to an able man added more to output than she would add as a first wife to a less able one." Again leaving aside the tautological reasoning, this hypothetical result, an increase in total output over all marriages, is essentially empty as a motivating personal or social force in marital decisions.

As in many family decisions, especially those concerning fertility, the individual who decides does not ordinarily concern himself very much with his or her effects on the total output, or society as a whole. Thus, whether total output over all marriages is greater does not motivate people to enter polygyny. If Becker disclaims this as a motive, it is nevertheless obvious from the context that it is viewed as a partial explanation for the distribution of wives in a society.

Nevertheless, if we ask only about higher or lower monetary output of individual marriages, under Becker's assumptions we could expect that able men would try to get a second wife, and their chances of success would be greater than those of less able men.

If nothing else were involved, we could be satisfied that the unequal distribution of wives among the total number of husbands is now explained, at least from the man's side (from the woman's side, the matter is less clear, since under polygyny the husband takes a much larger share than the wife does). Indeed we might then take a step further and predict which economic strata of men would be able to reap this advantage, and even how much they would pay in order to make this investment in a wife, as compared with alternative investments in other types of capital goods. Where, for example, as in much of Central Africa, women may earn money by engaging in small-scale trading, or by tilling their own gardens for the family, we might even be able to put real monetary values on this kind of investment. Moreover, we might even give a better explanation for polyandry than Becker essays, since for the most part such systems occur where the productivity of a given man is low and he has little to invest in a wife, so that a set of men (often brothers) pool their assets in order to enjoy the benefits of one wife. ${ }^{2}$

However, reasoning from market or monetary total output, whether of the marriage or of all marriages, would miss the importance of women as goods, of women as producers of children, of women as links in purchasing political power, of women as prestige commodities, for monetary reasoning would not predict that women would be added where their monetary market output drops or almost stops upon entering marriage. For the stubborn fact remains that multiple marriage is most common among the

2 In polyandry these are often brothers, perhaps because this causes less strife; and this alleviates somewhat the problem of producing one's own children, which Becker speaks of as a goal in marriage. In any event, whether or not the husbands are brothers, there are usually rules to decide who is sociologically defined as father of a given child. 
stratum that gets the least monetary economic output from wives, that is, the most powerful and rich, who are most likely to wall them up and use them as pets, display them as objects that prove the man's high position, use them in power linkages, or even allow them to become parasites who destroy the family wealth by their extravagance. Indeed, it seems reasonable to assert that the higher the class position, the greater the likelihood of some polygynous arrangements, but equally the greater the likelihood that wives represent net losses, except in purely nonmarket goods. Like some other monetary goods, they are in part "bought in special markets"; they are also like such goods in another respect, for instance, furs, polo ponies, Rolls Royces, in that they can be put to other practical uses, and in revolutions sometimes are.

Thus, I am asserting that the reasoning of Becker's paper sometimes goes awry not because it uses economic reasoning in nonmarket areas, but because it fails to take note of the powerful nonmarket variables, whose effects may run counter to those of income variables, however these latter are aggregated. Nor am I as yet sure that market prices or decisions "prove" the total output is greater, whether of general nonmonetary or monetary goods, under these arrangements. As Frederick Knightsaid more than half a century ago, all suppliers are partially monopolies; and we know that these markets are rigged.

In a parallel fashion, the reasoning fails in its attempt to explain the decline of polygyny, that is, the system, in our time and to some extent (although the facts are less clear) over a longer period of time-less clear because we suppose that never in the history of the recent world have most nations been polygynous except under rare conditions.

After flirting with a biological explanation, Becker involves himself in a complex refutation of the claim that women would be better off economically if polygyny were abolished (see his section 3, above). But his argument, and those he tries to refute, are essentially irrelevant, because all of them still seem to refer to the total market output of the household. It is much more likely that nonmonetary variables shape this decline in polygyny.

Here, as so often in such ventures into why social structures assume their sometimes peculiar shape, we have to ask, not merely about the nonmarket variables, but who decides: who organizes the market. In spite of Becker's graceful reference (n. 27) to Shaw's clever comment, the fact is that we have no evidence from any time or place that women ever created a polygynous system. It was men who established them, men whose command of force and force threat, prestige, and wealth was paramount in all the societies we know. Doubtless, some women did better economically under such systems, as some women in the United States would if they joined with other women to marry one rich and powerful man, but the system as a whole was not created by women; and wherever new laws, 
social movements, revolutionary ideologies, industrialization, urbanization, or religion permit them a free market choice they move away from polygyny. ${ }^{3}$

I shall not presume, especially in the midst of our contemporary turmoil about who has the right to report what women feel, to know precisely why women object to this system, although I think Becker's earlier, excellent analysis of caring and sharing are relevant. From the known fact that the birth rate under polygyny is less than under monogamy, and from the rules about equal sexual rights in polygynous systems, we must infer that women do not get as much tenderness, affection, and sexual enjoyment in those systems-again, we can use economic theory to reason about these variables, but they are not monetary. Men are in a much more influential position in such systems, and do not have to share as much of the physical output of the family, as indeed they also monopolize much of the prestige-esteem output of the family. They have the power to impose their own prices, in such systems. Thus, when external constraints, including money-market constraints, permit, women decline to enter such unions, even when they are still permitted.

I suggested earlier that after this critical commentary an important puzzle would still remain, although it is one that Becker has really not perceived clearly. It is why some social systems are polygamous, and others are not. An explanation of a system may not be adequate as an explanation of how some individuals act within it. The possibility that some men will benefit from taking more than one wife does not explain why polygyny occurs here rather than there-and it especially fails if we remember that even in most such systems the typical marriage is a pairing, one man to one woman. Why are such systems approved and viewed as an ideal, though few can attain it?

I do not think that any current explanations work well, though doubtless when one does it will be some sort of nonmarket economic analysis. That explanation would have to confront the fact that Western societies, including Latin America, of course, have not been polygynous in any historical period-and of course I do not mean only in the statistical or distributional sense, but in the normative sense, that polygyny was never a socially approved pattern of marriage. Both Japan and China have been mainly monogamous, though in both cases wealthy or powerful men could purchase additional concubines, and in China some of these came close to being recognized as "secondary wives" with specific rights. India, similarly, has been mainly monogamous, though again with a much more open acceptance of concubines. Perhaps most societies outside those great civilizations-but remember they encompass most of the

${ }^{3}$ See in this connection the relevant sections of my World Revolution and Family Patterns (1963), esp. chap. 4 on Sub-Saharan Africa. 
world's population-have been polygamous in the specific but narrow sense that some form of polygamy was normative, something to which men and families aspired.

Whatever those explanatory variables will turn out to be when we locate them, I rather suppose they will not be monetary, and-more important-their impact will be seen primarily among the people who dominated those sociopolitical systems and those marriage markets, that is, the upper-strata men. Upper-strata men created a set of constraints that defined the marriage and family market so as to yield great monetary and nonmonetary advantages to them.

Few good theories in the history of science "ffitted the facts" very well, and the "facts" at any given time were partly wrong, so that each explorer must follow his or her temperament rather than a rule which would ground new thinking only on the facts or only on free speculation. I do suspect, however, that a deeper sense of the crude regularities would not hinder these elegant flights, but might pose still more interesting puzzles for the imaginative economist. More fundamentally, I am at least partly persuaded by the work before us that in several fields we are moving toward a single structure of hypotheses about social behavior, hypotheses supported by research in several different fields under different labels; and that two decades hence we may discover we have created a rather impressive body of social science-if not "unified," at least mutually confirmatory. Becker's explorations are an important step in that progress. 